Netherlands, to promote the objectives of nature conservation. In Thailand the game law is being revised according to the experience of game laws in other countries, and the forest law, too, is also being examined since it is ineffective in preventing destruction; setting aside of the primitive regions as natural reserves and national parks is also under consideration. In the national budget of the Netherlands for 1961 a sum of about $2 \cdot 2$ million dollars has been earmarked for nature protection (as compared with the sum of 1.2 million dollars for 1959). 1.3 million dollars is intended for the purchase of reserves and 300,000 dollars for their management, figures which compare with 630,000 dollars and 210,000 dollars respectively for 1959. In addition, the personnel of the Institute of Ecological Research for Nature Protection has been increased from 16 in 1959 , to 21 .

\section{The City Museum, Sheffield}

THE combined annual reports of the City Museum, Sheffield, for the two years 1958-60 form an inspiring record of progress and initiative by a relatively small staff (Pp. $20+4$ plates. Sheffield: City Museum, 1961). The theme of service to the community underlies the work of this Museum. Prominent among its activities is that of evening opening in the summer until 8.30 p.m. and the organization of more than a hundred demonstrators at the Uneseo exhibition, "The Earth as a Planet". New displays include Saxon jewellery and metal-work, medieval pottery and sculpture, British bats, and one illustrating the variety and forms in extinct animals.

\section{South African Prehistory}

THE January and February issues of the South African Journal of Science contain articles of considerable interest to archæologists. R. J. Mason discusses the problem of the earliest tool-makers in South Africa, P. V. Tobias brings forward new evidence and new views on the evolution of man, and Gordon Cramb continues his report on the excavations undertaken at the Holley shelter near Wartburg, Natalthe first report appeared in the same journal as long ago as 1952. Mason's conclusions are certainly very interesting in view of the human finds of very early date in the region. He says that up to now in South Africa there is no evidence for stone tool-making earlier than the complex earlier Acheulean stage, which is possibly equivalent to Olduvai Gorge Bed 2 . There seems to be evidence at the limeworks site for the use of bone for tool-making purposes at an earlier date, but at present no stone implements have been found with them. Tobias does not agree with Dr. Wells, who has suggested that the basic human type in South Africa was possibly protosapiens. He claims that an early proto-sapiens such as that found at Kanam in Kenya is not early Pleistocene but Middle Pleistocene in date. He argues that the 'Rhodesioids' are derived from the African Middle Pleistocene hominids, and, in turn, these later gave rise to the Boskopoid and Bush types. Tobias also discusses the roles of cultural and natural selection in South African human evolution. A very extensive bibliography is appended. The Holley rock-shelter site has yielded artefacts belonging to the later Stone Ages from the upper layers. Below them a series of Middle Stone Age tools has been unearthed. From both these levels carbon samples were collected and these were analysed at the British
Museum. The results would seem to be : 18-in.24-in. layer 4,490 years \pm 150 years, and 24-in.30 -in. layer 18,200 years \pm 500 years.

\section{Instrumentation in Industry}

As a means of increasing the application of scientific method to industry, the Department of Scientific and Industrial Research has produced another of its popular booklets. This one, Instruments in the Factory, has been written by Dr. J. Thomson, director of the British Scientific Instrument Research Association, and shows that, despite the increasing use of instruments in modern manufacturing processes, there is still scope for improving instrumentation in most industries (Pp. 12. London: Department of Scientific and Industrial Research. 1961). Thermostatic control of water temperature is an example of how instrumentation can be extended. The smoke detector is another; its usefulness is easy to recognize, and the absence of smoke is a good indication of the efficient use of fuel. Another example occurs in flow measurement : often, particularly in smaller firms, accurate measurement of the flow of liquids in manufacturing processes can save a large amount of money. Simple robust methods are available. In the same way the 'thickness' of a liquid can also be measured with advantage. Manufacturers who would like to pass from 'instrumentation' to 'automation' will find from a study of this booklet that automatic control can often take very simple forms; instrumentation and automation can be used to improve products.

\section{Hyperon Stars}

THE extension of V. A. Ambartzumian's hypothesis of stellar evolution led G. S. Saakyan (Priroda, 11, $14 ; 1960)$ to develop a new hypothesis of stellar evolution based on the findings of certain recent discoveries of new elementary particles. According to this hypothesis dense stars of the type of "white dwarfs' on further contraction become neutron stars. During this process their density changes from approximately $10^{4} \mathrm{gm} . / \mathrm{cm} .^{3}$ to about $10^{8} \mathrm{gm} . / \mathrm{cm} .^{3}$. With a further increase of density to $10^{15} \mathrm{gm} . / \mathrm{cm} .^{3}$ these stars become hyperon stars representing a more stable state under such conditions. The mass of such hyperon stars in equilibrium is approximately the same as that of the Sun, while the size of their radius is of the order of a few kilometres. Only the central part of such stars contains hyperons. The outer zone is made of neutrons, while the outermost part is made of bare nuclei and electrons. The enormous pressure inside such stars is balanced by the force of gravity, but when such an equilibrium is disturbed hyperon stars are liable to explode with a terrific violence, not unlike the explosions leading to the formation of the 'nova' stars.

\section{Scientific Information Notes}

Scientific Information Notes for February-March 1961, issued by the National Science Foundation, notes that the Foundation is supporting a two-year investigation of the line-formula notation for representing chemical structural formulæ as lines arrays of symbols. This is part of an extensive study of chemical notation systems. The Foundation is continuing to support the Harvard University project for research on automatie translations and mathematical linguistics. It is also giving partial support to the abstracting office of the International Federation for Docu- 